\title{
Evolution of fast-track in bariatric surgery
}

Gómez-Diago L. ${ }^{1}$,Hernández-Cádiz M.J. ${ }^{1}$, Bruna M. ${ }^{2}$, Navarro C. ${ }^{2}$, Vicente-Fernández P. ${ }^{1}$, De Andrés J. ${ }^{1}$ ${ }^{1}$ Consorcio Hospital General Universitario de Valencia, Dept of Anaesthesiology \& Intensive Care; Dept of Surgery, Valencia, Spain

\section{Background and Goal of Study}

Nowadays, vertical sleeve gastrectomy (VSG) is one of the most popular method of weight-loss surgery. Fast-track rehabilitation in the postoperative care has increased with favorable results and without raising the associated morbidity and mortality.

Our aim is to evaluate the development of the multimodal rehabilitation measures applied. Moreover, the results obtained in the different periods were evaluated comparing the postoperative morbidity and mortality among the different periods.

\section{Materials and Methods}

Retrospective and comparative analysis of patients undergoing laparoscopic VSG between january 2010 and january 2016 in our center. Anthropometric parameters and comorbidities of all patients, hospital stay, surgical time, use of drainage and nasogastric tube, postoperative oral intake tolerance and mobilization were evaluated, comparing the annual evolution of each one.

\begin{tabular}{|l|l|l|l|l|l|l|}
\hline & \multicolumn{1}{|c|}{2010} & \multicolumn{1}{|c|}{2011} & \multicolumn{1}{|c|}{2012} & \multicolumn{1}{|c|}{2013} & \multicolumn{1}{|c|}{2014} & \multicolumn{1}{|c|}{2015} \\
\hline $\begin{array}{l}\text { Nasogastric tube } \\
\text { (patients) }\end{array}$ & $\begin{array}{l}8 \\
(33.3 \%)\end{array}$ & $\begin{array}{l}2 \\
(15.4 \%)\end{array}$ & $\begin{array}{l}2 \\
(7.1 \%)\end{array}$ & $\begin{array}{l}4 \\
(16 \%)\end{array}$ & $\begin{array}{l}4 \\
(19 \%)\end{array}$ & $\begin{array}{l}4 \\
(17.4 \%)\end{array}$ \\
\hline $\begin{array}{l}\text { Bladder catheter } \\
\text { (patients) }\end{array}$ & $\begin{array}{l}18 \\
(75 \%)\end{array}$ & $\begin{array}{l}9 \\
(69.2 \%)\end{array}$ & $\begin{array}{l}11 \\
(39.3 \%)\end{array}$ & $\begin{array}{l}14 \\
(56 \%)\end{array}$ & $\begin{array}{l}11 \\
(52.4 \%)\end{array}$ & $\begin{array}{l}5 \\
(21.7 \%)\end{array}$ \\
\hline $\begin{array}{l}\text { Mobilization } \\
\text { (median days) }\end{array}$ & 2 & 2 & 2 & 1 & 2 & 1 \\
\hline $\begin{array}{l}\text { Oral intake } \\
\text { tolerance (median } \\
\text { days) }\end{array}$ & 3 & 3 & 4 & 4 & 3,5 & 2 \\
\hline \begin{tabular}{l} 
Stay (median day) \\
\hline
\end{tabular} & $8.1(6)$ & $12.4(5)$ & $6.6(5)$ & $5.3(5)$ & $7.8(5)$ & $4.2(4)$ \\
\hline
\end{tabular}

Table 1.

\section{Conclusions}

The progressive application of different fast-track rehabilitation measures in postoperative period of VSG is safe and reliable. Protocolization of the actions and the multidisciplinary approach in these patients must be necessary to obtain optimal results.

\section{Results and Discussion}

134 patients were involved, no significant differences in the number of surgeries performed per year, neither in the BMI and associated comorbidities of the patients evaluated in each year were found. Laparoscopic surgery was permorfed in all patients and surgical time showed a downward and progressive trend (from 176 minutes in 2010 to 124 minutes in 2015). Postoperative stay (median 6 days in 2010 and 4 days in 2015), the use of nasogastric tube and bladder catheter after surgery (in 33.3 and $75 \%$ respectively of patients from 2010 to 17.4 and $21.7 \%$ in 2015), use of drainage (95.8\% in 2010 and $86.3 \%$ in 2015), early feeding (from 3 days in 2010 to 2 in 2015) and mobilization (from 2 days in 2010 to 1 in 2015). Associated morbidity was 20.8\% in 2010 and $27.2 \%$ in 2015. There was no mortality and the percentage of reinterventions was $16.6 \%$ in 2010 and $13.6 \%$ in 2015.

Results are shown in table 1.

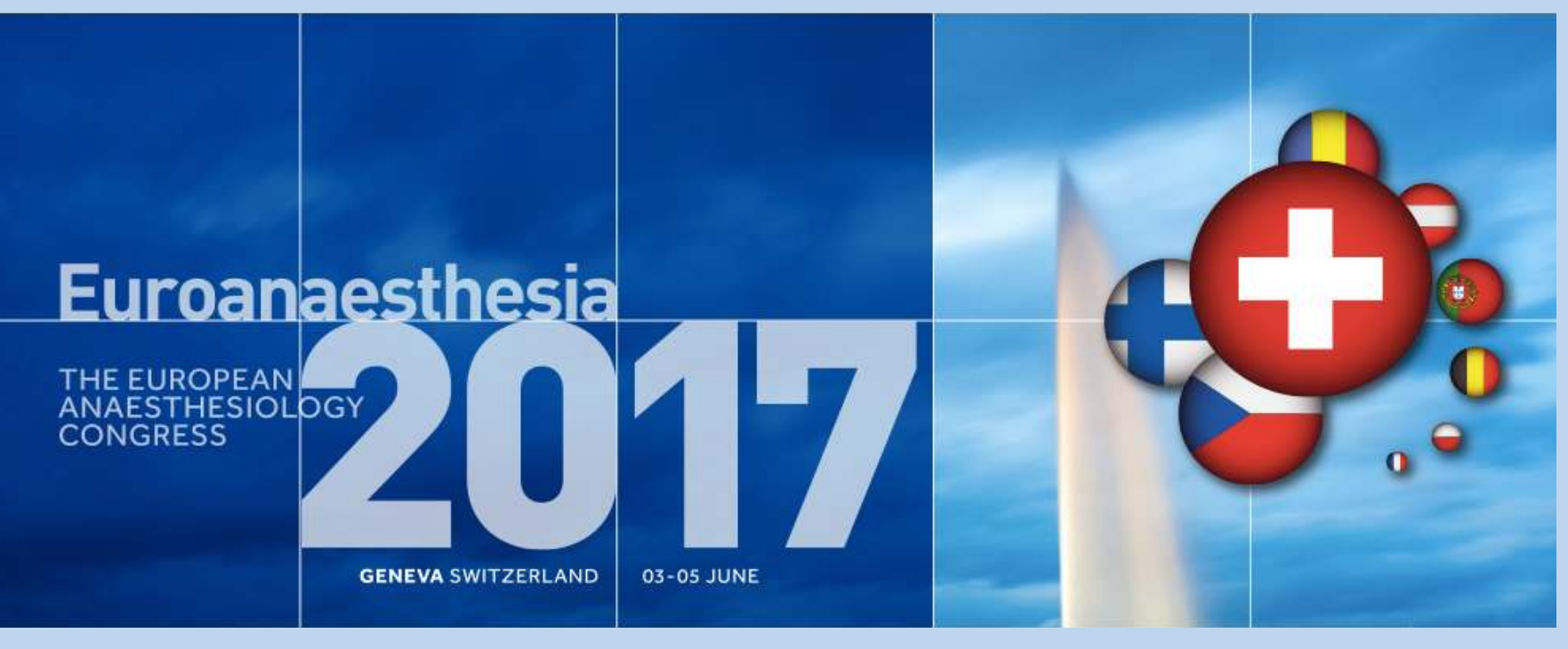

